\title{
Evaluation of the Efficiency of Government Programs' Development Systems
}

\author{
Irina Yurzinova \\ Department of Economic theory \\ Financial University under the Government of the Russian \\ Federation \\ Moscow, Russia \\ E-mail: IYurzinova@fa.ru
}

\author{
Valery Nezamaikin \\ Department of Finance and Credit \\ Russian State University for the Humanities \\ Moscow, Russian Federation \\ E-mail: NezamaikinVN@mail.ru
}

\begin{abstract}
The present article reviews the current problems of the realization of the Federal Law "On Strategic Planning in the Russian Federation", ensuring coordination and interaction in the development of government programs. The article suggests an approach to the estimation of the efficiency of coordination and interaction, which allows both increasing its efficiency, and reducing budget losses under the stage of government programs development.
\end{abstract}

Keywords-social and economic progress; government program; evaluation of the efficiency; strategic planning; system approach

\section{INTRODUCTION}

Nowadays in conditions of the urgency of increasing the efficiency of budget expenses, there is a topical problem of increasing the quality of the government programs development, particularly the government programs of the subjects of the Russian Federation.

Heedless of the fact that the Federal Law dated 28.06.2014 No.172-FL "On the Strategic Planning in the Russian Federation" (further - The Law "On the Strategic Planning in the Russian Federation", The Law 172- FL) is being implemented for more than three years, few topical problems are still not solved, impeding the efficient realization of the law [1]. A part of those problems was made public by the representatives of the Ministry of Economic Development at the scientific practical workshop of the Russian Federation regions and municipal educations of the Siberian Federal District on the implementation of the Law 172-FL (the Russian Federation, Novosibirsk, 19.05.2016). As it follows from the speech of E. S. Chuguevskaya, Head of the Department of Strategic and Territorial Planning of the Ministry of Economic Development, there is still no unified document system of the strategic planning, interconnected with the system of territorial and budget planning [2]. The result of this is the absence of the following:

- A clear-cut system of the complex strategic planning documents

- Hierarchical structure of the strategic planning documents system, its typology depending on the target purpose, and characteristics of the vertical and horizontal connections;

- Document connections of the strategic planning, depending on stages, indexes and implementation;

- Clear-cut mechanisms of realization of the strategic planning documents.

If to systematize and generalize the problems of realization of The Law 172- FL, they all come to two aspects:

- The problem of coordination and interaction of the government program developers;

- The problem of the government programs implementation.

Let us focus on the first aspect.

\section{APPROACH TO THE EVALUATION OF THE EFFICIENCY OF COORDINATION AND INTERACTION}

There are few main sources, which generate the problem of coordination and interaction:

- First, the country scale and the high power of the social and economic differences between the subjects of the Russian Federation;

- Second, the lack of technological security of the coordination at the federal level;

- Third, the lack of clear-cut mechanisms of the horizontal coordination and the coordination documents;

- Fourth, the deficit of specialists in the development of macro projects at the level of regional executive authorities.

The authors do not attribute the lack of the regulatory base of the government regional programs development to the source of this problem, but the availability of the regulatory base in a view of the Order on development, realization and evaluation of efficiency of government programs in a region of the Russian Federation is established 
by the Second Paragraph of The Law "On Strategic Planning".

Nowadays there are appropriate documents of the federal level, which could be taken as the basis for the first stage of the appropriate district documents development. Firstly, it is The Decree of Russian Federation Government from 02.08.2010 № 588 “On Establishing the Order of Development, Realization and evaluation of the Russian Federation government programs" ( further - The Decree No. 588) [3].

It should be noted that The Decree No. 588 holds few conditions, which reduce the overall efficiency of its realization. Nevertheless, its application as the basis for the development of district-level similar documents is purposeful, since this will allow resolution of such a main coordination problem as the providing of uniformity of demands of government program development in the regions of the Russian Federation.

From the accentuated sources of the coordination and interaction problem existence just the country scale should be considered as the restrictive condition, which determines the complication of the systems development, which help to solve any problem. All the other sources could be destroyed, or their influence could be minimized.

In this context, first, it is necessary to focus on the quality of its development at the first stage, not on the quality of documents being developed, which means to move the accent of the evaluation of efficiency from the end result to the process of preparation. After the process is set, the evaluation of efficiency of its realization could be moved to the second plan, leading the evaluation of efficiency of government programs to the first one.

Let's note one more topical moment. Apart from the solution of the problems of coordination and interaction, the shift of accent of the evaluation of efficiency to the process of preparation of planning documents will allow to solve one more topical problem: to optimize expenses for the government program development and to reduce the budget losses for this stage.

An important argument for the evaluation of the efficiency of the government programs system of development for an economic basis is that such evaluation can help to take the numerical easily interpreted result, which could be used in different comparative researches.

Relying on this condition, the efficiency of the function of the planning system could be understood as the degree of economical legitimacy of expenses, which the subject of management bears because of the system functioning. Interestingly, the degree of utility of planning will be a more adequate criterion, however, the term "utility" should be specified. Besides, it is more comfortable to evaluate the "utility" with the economic methods with the help of evaluating the legitimacy of expenses.

The complication of the social-economic problems of development, which are resolved at the federal and regional levels, generates the complication of modern systems of the strategic planning. All these lead to the choice of the system approach as the most effective and the only methodological base of evaluation. From the positions of the system approach we can talk about three main aspects of the evaluation of the process of the government program development:

- Administrative

- Organizational

- Technological

The administrative aspect should reflect the efficiency of the functioning of the system of strategic planning as a part of the whole government system development. Traditionally, the evaluation if the system development is made by the quality of an administration (by the result of administrating or administrative product) or by the ending condition of the administrative object, however in macroeconomic planning there are objective difficulties in both versions.

In the first case the evaluation has to be based on the construction quality of a government program. It is easier and more logical to make it by analyzing results of the numbers of government program changes during its implementation or by the deviations of actual values, which were taken by the results of the government program realization and how much they differ from the planned changes. These both evaluations can be purposefully used, but let us not attach much importance to them. The complication is that government program changes and deviations of actual values from the planned changes are not always the consequence of the bad quality of the program preparing. Probably, they arise by the influence of essential changes of conditions of external and inside space, which the system of strategic planning couldn't consider during the government program development because of objective differences of its organization and the complication of the social-economic system, which is the subject of administration. Both reasons of the deviation and changes appearance are the lack of quality preparing for the government program and the influence of conditions of external and inside space, which were changed, these reasons are not obvious and connected to each other closely, that's why it is practically impossible to evaluate the objective proportion of the government program quality decline, which is the part of the strategic system planning calculation. The problem of evaluation will become more insolvable if the evaluation of the strategic system planning administrating quality will be made based on the missed benefit value, which the government did not take during the planning calculation.

In the second case the evaluation should be made by the last condition of the administrated subject, which is the social-economic system of the federal or regional level. The main problem here is detecting the objective proportion of the attained result, appeared in the result of the strategic planning diligence, not because of the external and inside space changes, circle processes of social-economic development, etc. It is rather hard to resolve the problem of evaluation in such a form even at the level of a separate 
organization, and it is insolvable at the macroeconomic level at large.

Additional possibilities for the strategic system planning administrating quality appear when the system is built in such a way when its functions include the working agreement of different subjects over resources debarment, because of the inconsistency during the government program realization. In this case it's possible to speak about the part of the achieved result is really the merit of the planning system, which functioning didn't allow to make inexpedient expenses. The measure of conformity and the role of it's achieving in the strategic planning system can be evaluated by the analyzing the working materials results in department and interdepartmental working groups, which are made for solving the problems of government programs development and realization. However, not just problems of the resourcing expenses prevention are controlled by these working groups during the government program realization with the help of the providing the inside conformity of the government program, but different problems of interaction organization too. In this case just the part of the working group results should be used as the basis of evaluation, which connects the problems of the elements and parts agreement of the main program.

In such a way, it is purposefully to evaluate the quality of administration of the government programs development process by making the analysis:

- The number and the essence of any government program elements corrections in the course of implementation;

- Deviations of actual values and target indexes and the government program detectors from the planning values with the required reason analysis of such deviations;

- Work materials of the working group, which functions include the problems of coordination and interaction during the government program development in the part of providing the inside agreement of the program.

We'll notice that the evaluation for all three directions is possible to be made just by the expert way, which rises the subjectivity and reduces the accuracy and authenticity of evaluation. However, this complication can be overpassed with the considered approach of forming evaluation criterions and evaluation procedure development.

Organizational aspect of the evaluation factors in the complicated process of the modern system of planning that includes all the areas of action and needs coordinated interaction of a big number of entities (government agencies, public institutions. departments of interethnic cooperation, etc.). Violation of the coordination of the latter inevitably produces a big number of negative consequences, first of all, to the resources overspending for the government program realization and declining its quality.
The quality of the organizational interaction can be evaluated in different directions, however it is purposefully to emphasize two basic:

- Management of the work of the strategic planning system: the main accent should be necessarily made to the identification of resources overspending in the planning, for example, following the functions' duplication, inside the system) [4];

- Management of the information interaction between the participants of the planning system, which is purposefully evaluated following the analyzing the quality characteristics of the information and channels exchange: timeliness, fullness, relevance, efficiency of representation, form and correction ability, comparability, etc.

The main problem of the normal evaluation of the organizational aspect of the strategic planning system functioning is that the evaluation criterions have the quality character here generally. As a consequence, there is a necessity for a normal determination for threshold meanings of the «quality» ranges. So, in the decision of the problem (in the easiest way)- which of the numerical meanings of the evaluation criterions are allowable and with which of them the organization planning system needs the immediate correction.

The last main aspect is the evaluation of technologies, used in the strategic planning system, because not just the value of costs for the planning document development depends on them in modern planning systems, but the effective decision of many interconnection problems, agreement and organization.

Several general criteria of the technological provision evaluation of the government programs development, which purposefully can be used in any occasion, can be put forward:

- Frequency of the used technologies corrections;

- A part of special researches during the government programs development, requiring engagement of nonstandard technologies;

- A part of operations in the development administrative system and the government programs implementation, conducted past the planning system due to imperfection of the used technologies, etc.

It should be noted that making special technological decisions substantially expands the opportunities of the planning system as it:

- Increases the speed and accuracy of the information processing, allows increasing substantially the amount of the processed information;

- Allows using the scenario approach and spending a priority model experiments [5];

- Reduces the level of subjectivity inside the planning and others. 
However, those special technological decisions should be used 'full time', purposefully and on a standard basis. Application of these technologies is chaotic, depending on the situation and would inevitably cause additional costs under the government program development and would increase the probability of mistakes.

Three aspects of the efficiency evaluation of the government programs development management are considered. It should be noted that they intercross and mutually complement each other. For the terminal stage of the evaluation it is necessary to make decision on the strategic planning system's efficiency because of the result synthesis of the evaluation under these three aspects [6]. A complex evaluation is possible using one of the following widespread methods:

- Expert evaluation - this method's bonus is simplicity and low resource capacity, the drawback is the subjectivity of the result;

- Score evaluation - its bonus is the opportunity of the simple joint accounting of non-added results directly; its problem is typical for all score systems of evaluation (primarily, the complication of the evaluation scale development and suchlike).

- Weighting score - the main bonus of this method is the opportunity of unequal accounting of different evaluation directions or estimated possessions; the problem is the complication of determination of the weighting coefficients [7].

\section{CONCLUSION}

To sum up, it should be noted that the proposed method allows improving efficiency of the coordination and interaction during the process of the government programs development, on the one hand, and on the other hand, improving efficiency of the expenditure that the budget bears under the government program development. Wherein the method has the low resource capacity because it does not involve special researches practically, which need considerable resource costs.

\section{REFERENCES}

[1] The Federal Law dated 28.06.2014 № 172-FL “On Strategic Planning in the Russian Federation".

[2] E.S. Chuguevskaya, Conceptual basics of the document system formation of the strategic planning of a district development. Materials of the scientific practical workshop for the Russian Federation subjects and municipal educations of Siberia Federal District on realization of The Law 172-FL "On strategic planning in the Russian Federation" (Novosibirsk, 19.05.2016) // access mode: http://economy.gov.ru/minec/about/structure/depstrateg/20160606 (date of handling is 14.05.2017)

[3] The Decree of the Government of the Russian Federation as of 02.08.2010 No. 588 "On Establishing the Order on development, realization and evaluation of the Russian Federation government programs".

[4] V.N. Nezamaikin, I.I. Yurzinova, Budgeting: methodology or an instrument// Finance and Credit, 2012, No. 44 (524), pp. 16-21.
[5] V.N. Nezamaikin, I.I. Yurzinova, Priori evaluation of the consequences of a financial decision made in the course of planning company activities // Modern Science: topical problems of theory and practice. Series: Economy and law, 2011, No. 2, pp. 65-68.

[6] I. M. Syroejin, The perfection of system indexes of efficiency and quality. W.: Economy, 1980.

[7] V.N. Nezamaikin, I.I. Yurzinova, The criterion of the administrative efficiency evaluation of a nature-resource territory complex // Finance and credit. 2006, No. 19 (223), pp. 25-31. 